\title{
Study of biofilm formation and antibiotic resistance pattern of gram-negative Bacilli among the clinical isolates at BPKIHS, Dharan
}

\author{
Rabina Dumaru*, Ratna Baral and Lok Bahadur Shrestha
}

\begin{abstract}
Objectives: Gram-negative bacilli are the common causative agents for community-acquired, nosocomial and opportunistic infections. The recent upsurge of biofilm, as well as beta-lactamases producing strains, have synergistically led to the extensive dissemination of multi-drug resistant gram-negative bacilli. This study was carried out with an intention to detect the biofilm formation by gram-negative bacilli and determine their antibiogram along with the detection of extended-spectrum beta-lactamases (ESBLs) and metallo-beta-lactamases (MBLs) production.

Results: Among 314 isolates, Escherichia coli (38\%) were the predominant isolates followed by Acinetobacter spp. (20\%), Klebsiella spp. (16\%), and Pseudomonas spp. (12\%). Overall, 197 (62.73\%) of isolates were biofilm positive. 84 (26.75\%) and 51 (16.24\%) were confirmed as ESBL and MBL producers respectively. The association between MBL production and biofilm formation was statistically significant $\left(X^{2}=10.20, P\right.$ value $\left.=0.002\right)$ whereas it was insignificant between $E S B L$ and biofilm production $\left(x^{2}=0.006, P\right.$-value $\left.=0.937\right)$. Most of the biofilm and MBL producing strains were multi-drug resistant.
\end{abstract}

Keywords: Gram-negative bacilli, Extended-spectrum beta-lactamases, Metallo-beta-lactamases, Biofilm, Multi-drug resistant

\section{Introduction}

Gram-negative bacilli, most commonly Escherichia coli, Klebsiella pneumoniae, Pseudomonas aeruginosa, and Acinetobacter baumannii are responsible for causing various pathological diseases like UTIs, septicemia, pneumonia, nosocomial infections, opportunistic infections etc. [1]. Beta-lactams were wonder drugs until the dissemination of beta-lactamases (ESBL and MBL) producing strains were detected. "extended-spectrum betalactamases (ESBLs) may be defined as plasmid-mediated enzymes that hydrolyze oxyimino-cephalosporins (ceftriaxone, cefotaxime, and ceftazidime) and monobactams (aztreonam) but not cephamycins or carbapenems. They are inhibited in vitro by clavulanate" [2]. Metallo-betalactamases (MBLs) are carbapenems hydrolyzing

*Correspondence: uramud85@gmail.com

Microbiology \& Infectious Diseases, B.P Koirala Institute of Health

Sciences, Dharan 56700, Nepal enzymes; inhibited by metal chelating agents like EDTA $[3,4]$.

Biofilms are the bacterial aggregates firmly lodged in the extracellular matrices of polysaccharides, proteins, enzymes, and nucleic acids; thereby, facilitating anchorage to any surfaces irreversibly $[5,6]$. The matrix confers antibiotic resistance through processes such as expression of chromosomally encoded resistant genes, restriction of antibiotics, reduction in growth rate, and even counteracting the host immunity $[5,7,8]$.

The biofilm formation and beta-lactamases production synergistically contribute for extensive dissemination of multi-drug resistant strains of gram-negative bacilli. They are responsible for implicating chronicity, persistence, and relapse of infections leading to high morbidity and mortality; thus, posing a serious health crisis $[9,10]$.

In this regard, the knowledge of biofilm formation and antibiogram of bacterial isolates is of utmost importance for rendering reliable empirical antibiotic therapy to the patients [11]. Irrespective of development of numerous 
molecular detection techniques, the conventional methods are economical and reliable for the routine screening and diagnosis $[8,12]$. Hence, this study was conducted to detect the biofilm formation by gram-negative bacilli and determine their antimicrobial resistance pattern along with the detection of ESBL and MBL production.

\section{Main text Methods}

This cross-sectional study was conducted at the Department of Microbiology in B.P. Koirala Institute of Health Sciences (March-June, 2018). 314 non-repetitive gramnegative isolates were recovered from the clinical specimens (blood, urine, pus, CSF, endotracheal tube, tracheal aspirate, fluids, lesion swab, genital swab, catheter tips, sputum) submitted to the microbiology lab for routine culture and sensitivity testing. The samples were received from various inpatients wards and outpatient departments of this hospital. All specimens were inoculated on Blood and MacConkey agar except urine specimens which were plated on Cysteine Lactose Deficient Medium (CLED) as per the standard bacteriological procedures. The culture plates were incubated at $35{ }^{\circ} \mathrm{C}$ for 24-48 h. The growth isolates were identified on the basis of colony morphology, pigmentation, odor, and their unique biochemical tests [1].

\section{Antibiotic susceptibility test [13]}

It was performed on Muller Hinton agar by Kirby Bauer disc diffusion method following CLSI guidelines. Ofloxacin $(5 \mu \mathrm{g})$, levofloxacin $(5 \mu \mathrm{g})$, ceftazidime $(30 \mu \mathrm{g})$, cefepime $(30 \mu \mathrm{g})$, amikacin $(30 \mu \mathrm{g})$, gentamicin $(10 \mu \mathrm{g})$, piperacillin $(100 \mu \mathrm{g})$, piperacillin-tazobactam $(100 / 10 \mu \mathrm{g})$, imipenem $(10 \mu \mathrm{g})$, and colistin $(10 \mu \mathrm{g})$ were tested as common antibiotics for all strains. Polymyxin B (300 units), tobramycin $(10 \mu \mathrm{g})$ and carbenicillin $(100 \mu \mathrm{g})$ were added for Pseudomonas spp.

\section{Phenotypic detection of ESBL and MBL production [13, 14]}

The ceftazidime resistant strains were screened for ESBL production by using disc diffusion test. The increase in the zone of the diameter of $\geq 5$ - $\mathrm{mm}$ between ceftazidime $(30 \mu \mathrm{g})$ and ceftazidime-clavulanate $(30 / 10 \mu \mathrm{g})$ was considered ESBL positive [14].

Whereas, imipenem-resistant strains were tested for MBL production by combined disc diffusion assay using two imipenem discs, one with added $10 \mu \mathrm{l}$ of $0.5 \mathrm{M}$ EDTA. The increased zone of inhibition of $>7 \mathrm{~mm}$ around the imipenem-EDTA disc in comparison to zone size of imipenem disc alone was confirmed positive for MBL production [14].

\section{Biofilm detection by tube adherence and Congo red agar methods}

Tube adherence method [15] A growth organism was inoculated into trypticase soy broth and incubated for $24 \mathrm{~h}$ at $35^{\circ} \mathrm{C}$. After discarding the supernatant, the tube was washed with phosphate buffer saline. It was treated with $0.1 \%$ crystal violet for staining and then washed with water and dried. The appearance of visible biofilm lining the bottom and wall of the tube was considered positive.

Congo red agar method [16-18] The organisms were inoculated on Congo red agar plate and incubated at $37^{\circ} \mathrm{C}$ for $24 \mathrm{~h}$. The formation of black colonies indicated biofilm production.

\section{Results}

Out of 2562 samples received during the study period, only 314 were gram-negative bacilli showing the total growth rate of $12.25 \%$. 314 isolates were distributed as Escherichia coli (38\%), Acinetobacter spp. (20\%), Klebsiella spp. (16\%), Pseudomonas spp. (12\%), Enterobacter spp. (9\%), Citrobacter spp. (2\%), Proteus spp. (2\%), Providencia stuartii (1\%), and Salmonella Typhi (1).

\section{Antimicrobial resistant pattern (Table 1)}

Among all the tested antibiotics, most strains were found to be highly resistant to ceftazidime whereas all strains were sensitive to colistin.

\section{Biofilm detection}

A total of 197 (62.73\%) isolates were biofilm positive as detected by either tube adherence or congo red agar method.

\section{Phenotypic detection of ESBL, MBL and biofilm production (Table 2)}

Majority of Klebsiella spp. (77.55\%) were observed to be biofilm producers followed by Pseudomonas spp. (73.68\%).

Among the suspected cases of ESBL and MBL producers, $84(26.75 \%)$ and 51 (16.24\%) were confirmed as ESBL and MBL producers respectively. $38.01 \%$ of $E$. coli were detected as ESBL producers showing comparatively higher incidence. Klebsiella spp. were found to be the highest MBL producers i.e., 26.53\% closely followed by Pseudomonas spp. (26.31\%). 
Table 1 Showing antibiotic resistance pattern

\begin{tabular}{|c|c|c|c|c|c|c|c|c|}
\hline Antibiotics tested & $\begin{array}{l}\text { Escherichia } \\
\text { coli (121) }\end{array}$ & $\begin{array}{l}\text { Acinetobacter } \\
\text { spp. (63) }\end{array}$ & $\begin{array}{l}\text { Klebsiella spp. } \\
\text { (49) }\end{array}$ & $\begin{array}{l}\text { Pseudomonas } \\
\text { spp. (38) }\end{array}$ & $\begin{array}{l}\text { Enterobacter } \\
\text { spp. (27) }\end{array}$ & $\begin{array}{l}\text { Citrobacter } \\
\text { spp. (8) }\end{array}$ & Proteus spp. (5) & $\begin{array}{l}\text { Providencia } \\
\text { stuartii (2) }\end{array}$ \\
\hline Amikacin & $13.22 \%$ & $44.44 \%$ & $40.81 \%$ & $34.21 \%$ & $33.33 \%$ & $12.5 \%$ & $40 \%$ & $0 \%$ \\
\hline Gentamicin & $23.97 \%$ & $50.79 \%$ & $46.94 \%$ & $34.21 \%$ & $48.14 \%$ & $25 \%$ & $60 \%$ & $50 \%$ \\
\hline Ofloxacin & $61.98 \%$ & $55.56 \%$ & $57.14 \%$ & $31.58 \%$ & $37.03 \%$ & $12.5 \%$ & $60 \%$ & $50 \%$ \\
\hline Levofloxacin & $51.24 \%$ & $52.38 \%$ & $55.1 \%$ & $31.58 \%$ & $29.63 \%$ & $25 \%$ & $60 \%$ & $0 \%$ \\
\hline Ceftazidime & $61.98 \%$ & $73.02 \%$ & $75.51 \%$ & $36.84 \%$ & $51.85 \%$ & $50 \%$ & $40 \%$ & $100 \%$ \\
\hline Cefepime & $52.07 \%$ & $71.43 \%$ & $59.18 \%$ & $36.84 \%$ & $44.44 \%$ & $50 \%$ & $40 \%$ & $50 \%$ \\
\hline Imipenem & $21.49 \%$ & $39.68 \%$ & $53.01 \%$ & $31.58 \%$ & $37.03 \%$ & $0 \%$ & $60 \%$ & $0 \%$ \\
\hline Piperacillin & $56.19 \%$ & $55.56 \%$ & $63.27 \%$ & $31.58 \%$ & $44.44 \%$ & $62.5 \%$ & $60 \%$ & $0 \%$ \\
\hline $\begin{array}{l}\text { Piperacillin-Tazo- } \\
\text { bactam }\end{array}$ & $19.0 \%$ & $46.03 \%$ & $40.82 \%$ & $21.01 \%$ & $33.33 \%$ & $25 \%$ & $40 \%$ & $0 \%$ \\
\hline Colistin & $0 \%$ & $0 \%$ & $0 \%$ & $0 \%$ & $0 \%$ & $0 \%$ & N/A & N/A \\
\hline Polymyxin B & & & & $10.53 \%$ & & & & \\
\hline Tobramycin & & & & $31.58 \%$ & & & & \\
\hline Carbenicillin & & & & $39.47 \%$ & & & & \\
\hline
\end{tabular}

Not applicable (N/A) as they are intrinsically resistant

PolymyxinB, Tobramycin, and Carbenicillin were applied only for Pseudomonas spp.

Table 2 Distribution of biofilm formers and ESBL and MBL producers on the basis of specific organisms

\begin{tabular}{llllll}
\hline Organisms & $\begin{array}{l}\text { Biofilm formers } \\
\text { no. (\%) }\end{array}$ & $\begin{array}{l}\text { ESBL producers } \\
\text { no. (\%) }\end{array}$ & $\begin{array}{l}\text { MBL producers } \\
\text { no. (\%) }\end{array}$ & $\begin{array}{l}\text { Both ESBL and MBL } \\
\text { producers no. (\%) }\end{array}$ & $\begin{array}{l}\text { ESBL, MBL and biofilm } \\
\text { producers no. (\%) }\end{array}$ \\
\hline Escherichia coli (121) & $73(60.33 \%)$ & $46(38.01 \%)$ & $11(9.09 \%)$ & $3(2.48 \%)$ & $3(2.48 \%)$ \\
Acinetobacter spp. (63) & $34(53.97 \%)$ & $10(15.87 \%)$ & $13(20.63 \%)$ & $1(1.59 \%)$ & $1(1.59 \%)$ \\
Klebsiella spp. (49) & $38(77.55 \%)$ & $15(30.61 \%)$ & $13(26.53 \%)$ & $3(6.12 \%)$ & $3(6.12 \%)$ \\
Pseudomonas spp. (38) & $28(73.68 \%)$ & $6(15.79 \%)$ & $10(26.31 \%)$ & $2(5.26 \%)$ & $2(5.26 \%)$ \\
Enterobacter spp. (27) & $16(59.26 \%)$ & $2(7.41 \%)$ & $3(11.11 \%)$ & $1(3.70 \%)$ & 0 \\
Citrobacter spp. (8) & $5(62.50 \%)$ & $2(25 \%)$ & 0 & 0 & 0 \\
Proteus spp. (5) & $2(40 \%)$ & $1(20 \%)$ & $1(20 \%)$ & 0 & 0 \\
Providencia stuartii (2) & $1(50 \%)$ & $2(100 \%)$ & 0 & 0 & 0 \\
Total (314) & $197(62.73 \%)$ & $84(26.75 \%)$ & $51(16.24 \%)$ & $10(3.18 \%)$ & $9(2.87 \%)$ \\
\hline
\end{tabular}

\section{Association of ESBL and MBL production with biofilm}

\section{formation}

Although maximum ESBL producers were biofilm positive, no statistical significance was observed. $\left(\chi^{2}=0.006, P\right.$-value $\left.=0.937\right)$.

The association between MBL production and biofilm formation was found to be statistically significant. $\left(X^{2}=10.20, P\right.$-value $\left.=0.002\right)$.

\section{Association of ESBL, MBL and Biofilm production with antibiotic resistance (Table 3)}

There was a significant association of ESBL production and biofilm formation to antibiotic resistance. For all antibiotics except polymyxin $B$, the association between
MBL production and antibiotic resistance was noted to be statistically significant $(P$-value $=0.001)$.

\section{Discussion}

In this study, 314 g-negative strains were obtained. E. coli was the most prevalent pathogen with the occurrence of $38 \%$; identical to the results recorded by Fatima et al. (38\%) [19]. Several studies reported E. coli to be the most isolated GNB causing septicemia, UTIs and other infections [19-22]. The incidences of Acinetobacter spp. (20\%) and Pseudomonas spp. (12\%) in our study coincide with the findings of Sundaram et al. (21\%) and Mshana et al. $(12.2 \%)$ respectively $[21,23]$.

On account of antibiotic resistance pattern, almost all organisms were highly resistant to ceftazidime. This is probably due to the widespread use of third-generation 
Table 3 Showing association between antibiotics resistance, ESBL production, MBL production, and biofilm production

\begin{tabular}{|c|c|c|c|c|c|c|c|c|c|}
\hline \multirow[t]{3}{*}{ Antibiotics } & \multicolumn{3}{|l|}{ ESBL } & \multicolumn{3}{|l|}{ MBL } & \multicolumn{3}{|l|}{ Biofilm } \\
\hline & \multicolumn{2}{|l|}{ Resistance (\%) } & \multirow[t]{2}{*}{$P$-value } & \multicolumn{2}{|l|}{ Resistance (\%) } & \multirow[t]{2}{*}{$P$-value } & \multicolumn{2}{|c|}{ Resistance (\%) } & \multirow[t]{2}{*}{$P$-value } \\
\hline & Producers (\%) & $\begin{array}{l}\text { Non- } \\
\text { producers } \\
\text { (\%) }\end{array}$ & & Producers (\%) & $\begin{array}{l}\text { Non- } \\
\text { producers } \\
\text { (\%) }\end{array}$ & & Formers (\%) & Non-formers (\%) & \\
\hline Amikacin & 22.61 & 30.43 & 0.174 & 84.31 & 17.49 & 0.001 & 34.52 & 17.95 & 0.002 \\
\hline Gentamicin & 41.67 & 35.21 & 0.295 & 82.35 & 28.13 & 0.001 & 42.64 & 27.35 & 0.007 \\
\hline Ofloxacin & 69.04 & 46.52 & 0.001 & 96.08 & 44.11 & 0.001 & 57.87 & 43.59 & 0.01 \\
\hline Levofloxacin & 58.33 & 42.6 & 0.013 & 94.12 & 37.64 & 0.001 & 54.31 & 34.19 & 0.001 \\
\hline Cefepime & 84.52 & 43.48 & 0.001 & 94.12 & 46.77 & 0.001 & 59.39 & 46.15 & 0.023 \\
\hline Ceftazidime & 100 & 47.82 & 0.001 & 96.08 & 55.13 & 0.001 & 66.5 & 53.85 & 0.026 \\
\hline Imipenem & 26.19 & 35.22 & 0.132 & 100 & 19.77 & 0.001 & 39.09 & 22.22 & 0.002 \\
\hline Piperacillin & 72.62 & 45.65 & 0.001 & 90.19 & 45.62 & 0.001 & 57.87 & 44.44 & 0.021 \\
\hline Piperacillin-Tazobactum & 35.71 & 27.39 & 0.153 & 66.67 & 22.43 & 0.001 & 32.49 & 24.79 & 0.148 \\
\hline Colistin & 0 & 0 & * & 0 & 0 & * & 0 & 0 & * \\
\hline Polymyxin B & 16.67 & 9.38 & 0.241 & 20 & 7.14 & 0.079 & 10.71 & 10 & 0.33 \\
\hline Tobramycin & 66.67 & 25 & 0.067 & 80 & 14.28 & 0.001 & 35.71 & 20 & 0.233 \\
\hline Carbenicillin & 66.67 & 34.38 & 0.126 & 80 & 25 & 0.001 & 42.86 & 30 & 0.267 \\
\hline
\end{tabular}

PolymyxinB, Tobramycin, and Carbenicillin were applied only for Pseudomonas spp.

* No resistance was observed, P-value could not be calculated

cephalosporins without knowing the severity of infections [23]. In contrast, no strains were resistant to colistin.

Overall, $62.73 \%$ of isolates were detected as biofilm formers in our study. This is in agreement with the study led by Allam et al. (64.28\%) [24]. A similar study conducted in our center, BPKIHS, by Shrestha et al. recorded $71.8 \%$ isolates as biofilm producers [8]. The prevalence of biofilm producing Klebsiella spp. (77.55\%), Pseudomonas spp. (73.68\%), E. coli (60.33\%) and Acinetobacter spp. $(53.97 \%)$ in our study are in accordance with the studies of Allam et al. (72.72\%), Pittaya et al. (79.4\%), Allam et al. (55.77\%) and Gurung et al. (50\%) respectively [24-26]. The majority of biofilm producers were extracted from tissues, sputum, devices, and exudate samples supporting the fact that biofilm formation is facilitated by tissue lesions, implanted medical devices, chronic respiratory diseases, surgical wounds etc. [6, 9].

26.75\% strains were accounted as ESBL producers coinciding with Mshana et al. (29.8\%) [23]. The proportion of ESBL production in Nepal ranges from 18 to $62.7 \%$ [27]. Among the maximum isolated strains, the occurrence was higher for E. coli (38.01\%) comparable to the result of Sundaram et al. (35.3\%) [21]. The incidence of ESBL production by Klebsiella spp. in Nepal has been reported ranging from 4.1 to $90.9 \%$ supporting our finding [27, $28]$. Laudy et al. had the result of $15 \%$ ESBL producing $P$. aeruginosa equals to our finding [29]. Moreover, $16.24 \%$ were MBL positive, concomitant with Kamalraj et al. (18\%) [30]. Our study reported Klebsiella spp. (26.53\%), Pseudomonas spp. (26.31\%) and Acinetobacter spp. $(20.63 \%)$ as the major MBL producers which are in conformity with the data of Kaur et al. (34.8\%), Anuradha et al. (28.57\%) and Baniya et al. (22\%) for the respective organisms [18, 20,31]. The coexistence of biofilm along with both beta-lactamases producing strains was found to be $2.87 \%$. The biofilm matrix has been reported to enhance the expression of resistant genes like beta-lactamases [5, 7].

Despite the maximum ESBL producers being biofilm positive, no significant association was found between them, similar to the finding of Emami et al. but in contrast with other studies [17, 32, 33]. Conversely, the association between MBL production and biofilm formation was observed to be statistically significant. Although most of the antibiotics were resistant towards ESBL producers, the association was statistically insignificant. Amikacin followed by imipenem were found to be effective against ESBL producers. Except for polymyxin B, statistically significant association was established between MBL production and antibiotic resistance. Ceftazidime was $100 \%$ resistant to MBL positive strains, compatible with the study of Lyra et al. [34]. Besides, various studies have demonstrated MBL producers as pan drug-resistant strains signifying an alarming threat [35-37].

The association between biofilm and antibiotic resistance was noted to be statistically significant for aminoglycosides, fluoroquinolones, cephalosporins, 
imipenem, and piperacillin. A higher proportion of antibiotic resistance in biofilm producers in comparison to non-producers has been documented in many studies [35, 38-42]. No resistance was observed against colistin. It's the last viable option for multi-drug resistant strains either being non-producers or producers of ESBL, MBL and biofilm [20, 43].

\section{Conclusion}

The notable prevalence of biofilm-forming and multidrug-resistant organisms in our institution provides a glimpse of upcoming threat in our part of the world. The routine monitoring of biofilm and beta-lactamases production; therefore, can be recommended in clinical laboratories along with the strict implementation of infection control and prevention activities.

\section{Limitations}

The lack of confirmation of biofilm, ESBL, and MBL production by using molecular technologies are the drawbacks of this study.

\section{Abbreviations}

GNB: gram-negative bacilli; ESBL: extended-spectrum beta-lactamase; MBL: metallo-beta-lactamase; MDR: multidrug-resistant; UTI: urinary tract infection; CLSI: Clinical and Laboratory Standards Institute; EDTA: ethylene diamine tetra acetic acid.
\end{abstract}

\section{Authors' contributions}

Conceptualization: RD, RB, LBS. Investigation: RD. Methodology: RD, RB, LBS. Resources: RD, RB, LBS. Supervision: RB, LBS. Writing original draft: RD. Writing- review, and editing: RB, LBS. All authors read and approved the final manuscript.

\section{Acknowledgements \\ All members of Department of Microbiology of BPKIHS, Dharan.}

\section{Competing interests}

The authors declare that they have no competing interests.

\section{Availability of data and materials}

Available from the corresponding author on reasonable request.

\section{Consent to publish}

Not applicable.

\section{Ethics approval and consent to participate}

It was obtained from the Departmental Research Unit (DRU), an authorized wing of Institutional Review Committee (IRC), B.P. Koirala Institute of Health Sciences (BPKIHS), Reference No. 964/Micro/075.

Consent to participate: Informed consent was obtained from the participant.

\section{Funding}

None.

\section{Publisher's Note}

Springer Nature remains neutral with regard to jurisdictional claims in published maps and institutional affiliations.

Received: 1 November 2018 Accepted: 14 January 2019

Published online: 18 January 2019

\section{References}

1. Washington CW Jr, Stephen DA, William MJ, Elmer WK, Gray WP, Paul CSGL. Koneman's colour atlas and textbook of diagnostic microbiology. 6th ed. Philadelphia: Lippincott Williams \& Wilkins; 2006.

2. Thenmozhi S, Moorthy K, Sureshkumar BT, Suresh M. Antibiotic resistance mechanism of esbl producing enterobacteriaceae in clinical field: a review. Int J Pure Appl Biosci. 2014;2(3):207-26.

3. Nepal K, Pant ND, Neupane B, Belbase A, Baidhya R, Shrestha RK, et al. Extended spectrum beta-lactamase and metallo beta-lactamase production among Escherichia coli and Klebsiella pneumoniae isolated from different clinical samples in a tertiary care hospital in Kathmandu, Nepal. Ann Clin Microbiol Antimicrob. 2017;16:62.

4. Saffari M, Firoozeh F, Pourbabaee M, Zibaei M. Evaluation of metallo$\beta$-lactamase-production and carriage of bla-VIM Ges in Pseudomonas aeruginosa isolated from burn wound infections in Isfahan. Arch Trauma Res. 2016;5:4. https://doi.org/10.5812/atr.34343.

5. Macià MD, Rojo-Molinero E, Oliver A. Antimicrobial susceptibility testing in biofilm-growing bacteria. Clin Microbiol Infect. 2014;20(10):981-90.

6. Basak S, Rajurkar MN, Attal RO. Biofilms : a challenge to medical fraternity in infection control. Infect Control. 2013. https://doi.org/10.5772/55649.

7. Donlan RM. Biofilm formation: a clinically relevant microbiological process. Clin Infect Dis. 2001;33:1387-92.

8. Shrestha LB, Bhattarai NR, Khanal B. Comparative evaluation of methods for the detection of biofilm formation in coagulase-negative staphylococci and correlation with antibiogram. Infect Drug Resist. 2018;11:607-13.

9. Costerton JW, Stewart PS, Greenberg EP. Bacterial biofilms: a common cause of persistent infections. Science. 1999;284(5418):1318-22.

10. Jr CJS, Mende K, Beckius ML, Akers KS, Romano DR, Wenke JC, et al. Biofilm formation by clinical isolates and the implications in chronic infections. BMC Infect Dis. 2013;13:47. https://doi. org/10.1186/1471-2334-13-47.

11. Tanwar J, Das S, Fatima Z, Hameed S. Multidrug resistance: an emerging crisis. Interdiscip Perspect Infect Dis. 2014;2014:541340 [PMID: 25140175].

12. Mohamed A, Rajaa AM, Khalid Z, Fouad M, Naima R. Comparison of three methods for the detection of biofilm formation by clinical isolates of Staphylococcus aureus isolated in Casablanca. Int J Sci Res. 2016;5(10):1156-9. https://doi.org/10.21275/ART20162319.

13. CLSI. Clinical and laboratory standards institute. Document No M100. Performance standards for antimicrobial susceptibility testing: 27th edition. Wayne, USA: CLSI; 2017.

14. Yong D, Lee K, Yum JH, Shin HB, Rossolini GM, Chong Y. Imipenem-EDTA disk method for differentiation of metallo- $\beta$-lactamase-producing clinical isolates of Pseudomonas spp. and Acinetobacter spp. J Clin Microbiol. 2002;40(10):3798-801. https://doi.org/10.1128/JCM.40.10.3798 [PMID: 12354884].

15. Christensen G, Simpson WA, Younger JJ, Larry M, Barrett FF, Melton DM, et al. Adherence of coagulase-negative Staphylococci to plastic tissue culture plates: a quantitative model for the adherence of Staphylococci to medical devices. J Clin Microbiol. 1985;22(6):996-1006.

16. Freeman DJ, Falkiner FR, Patrick $S$. New method for detecting slime production by coagulase negative staphylococci. J Clin Pathol. 1989;42:872-4.

17. Neupane S, Pant ND, Khatiwada S, Chaudhary R, Banjara MR. Correlation between biofilm formation and resistance toward different commonly used antibiotics along with extended spectrum beta lactamase production in uropathogenic Escherichia coli isolated from the patients suspected of urinary tract infections visiting Shree Birendra Hospital, Chhauni, Kathmandu, Nepal. Antimicrob Resist Infect Control. 2016;5:5.

18. Baniya B, Pant ND, Neupane S, Khatiwada S, Yadav UN. Biofilm and metallo beta-lactamase production among the strains of Pseudomonas 
aeruginosa and Acinetobacter spp. at a Tertiary Care Hospital in Kathmandu. Nepal. Ann Clin Microbiol Antimicrob. 2017;16:70. https://doi. org/10.1186/s12941-017-0245-6.

19. Fatima S, Prasanthi K, Nagamani K. Comparative evaluation of biofilm production in Multidrug resistant and sensitive Gram negative clinical isolates. Int J Curr Microbiol Appl Sci. 2015;4(6):918-26.

20. Kaur N, Kaur A, Singh S. Prevalence of ESBL and MBL producing gram negative isolates from various clinical samples in a tertiary care hospital. Int J Curr Microbiol Appl Sci. 2017;6(4):1423-30.

21. Sundaram M, Babu D, Dhandapani K. A Study on correlation between the drug resistance and biofilm production among the GNB isolated from blood. Indian J Microbiol Res. 2016;3(2):197-202. https://doi. org/10.5958/2394-5478.2016.00045.5.

22. Hussain JH, Sharma A, Jaggi T, Mishra B, Thakur A, Dogra V, et al. Epidemiology of biofilm formation by Gram-negative bacilli in patients with urinary tract infection in a tertiary care hospital. Int J Heal Allied Sci. 2017;6:15-9. https://doi.org/10.4103/2278-344X.200206.

23. Mshana SE, Kamugisha E, Mirambo M, Chakraborty T, Lyamuya EF. Prevalence of multiresistant gram-negative organisms in a tertiary hospital in Mwanza, Tanzania. BioMed Cent. 2009;2:49. https://doi. org/10.1186/1756-0500-2-49.

24. Allam NG. Correlation between biofilm production and bacterial urinary tract infections: new therapeutic approach. Egypt J Microbiol. 2017:52:39-48.

25. Maita P, Boonbumrung K. Association between biofilm formation of Pseudomonas aeruginosa clinical isolates versus antibiotic resistance and genes involved with biofilm. J Chem Pharm Res. 2014;6(5):1022-8.

26. Khyriem A, Lyngdoh W, Banik A, Choudhury B, Bhattacharyya P, Gurung J. Association of biofilm production with multidrug resistance among clinical isolates of Acinetobacter baumannii and Pseudomonas aeruginosa from intensive care unit. Indian J Crit Care Med. 2013:17(4):214.

27. Pathak J, Pokharel N. Multidrug resistant and extended spectrum $\beta$-lactamase (ESBL) isolates from different clinical specimens. Int I Sci and Res Pub. 2015;5:1-5.

28. Raut S, Gokhale S, Adhikari B. Prevalence of extended spectrum betalactamases among Escherichia coli and Klebsiella spp. isolates in Manipal Teaching Hospital, Pokhara. Nepal. J Microbiol Infect Dis. 2015;5(2):69-75. https://doi.org/10.5799/ahinjs.02.2015.02.0179.

29. Laudy AE, Rog P, Stoczy A, Patzer J, Dzier D, Wolinowska R, et al. Prevalence of ESBL-producing Pseudomonas aeruginosa isolates in Warsaw, Poland, detected by various phenotypic and genotypic methods. PLoS ONE. 2017;12:6. https://doi.org/10.1371/journal.pone.0180121.

30. Kamalraj M, Kaviarasan K, Padmapriya G. Phenotypic detection of ESBL and MBL in clinical isolates of nonfermenters. Indian J Basic Appl Med Res. 2015;4(4):470-5.

31. De Anuradha S, Kumar S, Baveja SM. Prevalence of metallobetalactamase producing Pseudomonas aeruginosa and Acinetobacter Species in intensive care unit in a tertiary care hospital. Indian J Crit Care Med. 2010;14(4):217-9. https://doi.org/10.4103/0972-5229.76089.

32. Emami S, Eftekhar F. The correlation between biofilm formation and drug resistance in nosocomial isolates of Acinetobacter baumannii. Avicenna J Clin Microb Infec. 2015;2:2. https://doi.org/10.17795/ajcmi-23954.

33. Shanmugam K, Thyagarajan R, Katragadda R, Vajravelu L, Lakshmy A. Biofilm formation and extended spectrum beta lactamases (esbl) producers among the gram negative bacteria causing urinary tract infections. Int J Med Microbiol Trop Dis. 2017;3(3):86-90. https://doi.org/10.18231 /2455-6807.2017.0021.

34. Lyra PR, Cugati S, Anuradha K, Venkatesha D. Metallo beta lactamase producing Pseudomonas aeruginosa in a Tertiary Care Hospital. Int J Curr Microbiol Appl Sci. 2016;5(11):269-74.

35. Punia P, Goel N, Asati S, Phogat R, Chaudhary U. Biofilm detection amongst extended spectrum beta lactamase (ESBL) and metallo beta lactamase (MBL) producing clinical isolates of Acinetobacter baumannii. Int J Enchanced Res Med Dent Care. 2016;3:10.

36. Rao S, Karthika R, Singh S, Shashikala P, Kanungo R, Jayachandran S, et al. Correlation between biofilm production and multiple drug resistance in imipenem resistant clinical isolates of Acinetobacter Baumannii. Indian J Med Microbiol. 2008;26(4):333-7.

37. Mishra SK, Acharya J, Kattel HP, Koirala J, Rijal BP, Pokhrel BM. Metallo-beta-lactamase producing gram-negative bacterial isolates. J Nepal Heal Res Counc. 2012;10(22):208-13.

38. Ghadiri H, Vaez H, Azarkhiavi KR, Rezaee R, Noormohammadi MH, Rahimi AA, Vaez V, Kalantar E. Prevalence and antibiotic susceptibility patterns of extended-spectrum B-lactamase and metallo-ß-lactamase-producing uropathogenic. Lab Med. 2014;45(4):291-6.

39. Heydari S, Eftekhar F. Biofilm formation and $\beta$-lactamase production in burn isolates of Pseudomonas aeruginosa. Jundishapur J Microbiol. 2015:8:3. https://doi.org/10.5812/jjm.15514.

40. Pramodhini S, Niveditha S, Umadevi S, Kumar S, Stephen S. Antiobiotic resistance pattern of biofilm-forming uropathogens isolated from catheterised patients in Pondicherry, India. Australas Med J. 2012;5(7):344-8.

41. Shahidul KM, Farahnaaz F, Sunjukta A. Determination of Antibiotic resistance pattern of Biofilm producing Pathogenic Bacteria associated with UTI. Int J Drug Dev Res. 2013;5(4):312-9.

42. Shrestha LB, Bhattarai NR, Khanal B. Antibiotic resistance and biofilm formation among coagulase-negative staphylococci isolated from clinical samples at a tertiary care hospital of eastern Nepal. Antimicrob Resist Infect Control. 2017;6:89.

43. Vuotto C, Longo F, Balice M, Donelli G, Varaldo P. Antibiotic Resistance Related to Biofilm Formation in Klebsiella pneumoniae. Pathogens. 2014:3:743-58.
Ready to submit your research? Choose BMC and benefit from:

- fast, convenient online submission

- thorough peer review by experienced researchers in your field

- rapid publication on acceptance

- support for research data, including large and complex data types

- gold Open Access which fosters wider collaboration and increased citations

- maximum visibility for your research: over $100 \mathrm{M}$ website views per year

At BMC, research is always in progress.

Learn more biomedcentral.com/submissions 